\title{
Tophaceous gout of the rotator cuff: A case report
}

\author{
Sean T. O'Leary, FRCS (Tr\&Orth), Jerome A. Goldberg, FRACS, and William R. Walsh, PhD, Randwick, Australia
}

Soft-tissue tophaceous deposits have been reported in the finger, carpal tunnel, spine (cervical and lumbar), hip, knee, and Achilles tendon. $1,3,6,8,10,13,16$ Intraosseous and intradermal sites have also been described, and there is also a report of a tophus being the cause of fracture nonunion. ${ }^{4,5,17}$ Glenohumeral joint involvement in gouty arthropathy, however, is unusual. ${ }^{7}$

Tophaceous gout correlates with a longer duration of disease and a poor tolerance to medication. The clinical effects of intra-articular tophi are mostly caused by mechanical impingement. ${ }^{12}$ In the longer term, there is an increased rate of degenerative arthritis, although this association has been challenged. 8,11 We have been unable to find any previous reports of tophaceous gout occurring within the glenohumeral joint or rotator cuff. We present such a patient and discuss imaging, treatment, and further management.

\section{CASE REPORT}

A 48-year-old man presented with a 7-month history of anterior shoulder pain following an injury at work when lifting a heavy bag. He had previously been treated with a course of anti-inflammatory medication, 4 months of physiotherapy, and 3 subacromial injections, each of which provided short periods of relief.

On examination he had good power in his rotator cuff but had strongly positive signs of subacromial impingement. $\mathrm{He}$ also had a mild decrease in all ranges of motion, interpreted as a mild capsulitis. There were no symptoms or signs of any intra-articular mechanical derangement.

The patient's medical history revealed a 3-year history of gout without any specific medication. There were no cutaneous manifestations of gout and no other relevant medical history. An ultrasound revealed a hyperechoic lesion within the supraspinatus, presumed to have resulted from partial tearing. There were no other significant findings. Subsequently, magnetic resonance imaging (MRI), performed without contrast, did not demonstrate any significant findings except some supraspinatus tendinitis.

From the Orthopaedic Department and Orthopaedic Research Laboratories, University of New South Wales, Prince of Wales Hospital, and the Royal Berkshire Hospital, Reading, Berskhire R91 5AN, UK.

Reprint requests: Sean T. O'Leary, FRCS (Tr\&Orth), 2 Braybrooke Rd, Wargrave, Berkshire RG10 8DT, England (E-mail: sean.olearyl@btinternet.com).

J Shoulder Elbow Surg 2003;12:200-1.

Copyright (c) 2003 by Journal of Shoulder and Elbow Surgery Board of Trustees.

$1058-2746 / 2003 / \$ 35.00+0$

doi: $10.1067 / \mathrm{mse} .2003 .24$
When a course of conservative therapy had failed, the patient was admitted for an arthroscopic acromioplasty. A normal range of passive motion was noted with the patient under anesthetic. Findings at arthroscopy revealed a mild synovitis with crystals in the synovial fluid. Tophaceous deposits were noted both within the supraspinatus tendon (Figure 1) and at the upper edge of the subscapularis tendon (Figure 2). No attempts were made to remove the deposits. A standard arthroscopic acromioplasty was performed with division of the coracoacromial ligament.

The patient made an uneventful postoperative recovery with full resolution of his shoulder symptoms at 3 months. He was subsequently referred to his general practitioner for commencement of urate-lowering therapy.

\section{DISCUSSION}

The most common arthropathy to affect the glenohumeral joint is rheumatoid arthritis. ${ }^{14}$ Being that the glenohumeral joint is a synovial joint with a large subacromial bursa, it could be expected that it might be commonly affected by a crystalline arthropathy such as gout. This appears not to be the case, with pseudogout being more common. ${ }^{7}$

The presence of tophaceous gout correlates with a long duration of hyperuricemia and/or a poor response to uratelowering medications. Gouty tophi have been reported in many locations in patients both with and without known hyperuricemia, and their presence warrants the initiation or resumption of urate-lowering therapy. With the use of such therapy earlier in the disease process, the prevalence of gouty tophi appears to be declining. ${ }^{12}$ Acute synovitis may mimic septic arthritis, and the diagnostic presence of monosodium urate crystals within the joint fluid should be sought. The aspiration of unusual deposits, such as tophi, may also be performed for diagnostic microscopy. ${ }^{9}$

The imaging of tophi is more variable than may be expected of calcium-containing deposits. Gerster et al ${ }^{6}$ report on the use of computed tomography for intra-articular tophi of the knee, but outside of the knee, most reports comment on the use of MRI. ${ }^{15,18}$ Chen et al ${ }^{2}$ compared both modalities, and for MRI, they suggest that the appearance is characteristically of low to intermediate signal intensity on both $T_{1}$ - and $T_{2}$-weighting. $Y u$ et al, 18 however, report that appearances on $\mathrm{T}_{1}$-weighted imaging are relatively constant, with intermediate signal, whereas $T_{2}$ weighted imaging is more variable. There is enhancement with gadolinium, but the index of suspicion would need to be high to diagnose such a deposit clinically. Even with the benefit of operative hindsight, the tophaceous deposits could not be seen on our scans.

The presence of tophi within the cuff may result in secondary impingement either directly by local hyperemia and edema or indirectly through impairment of rotator cuff 


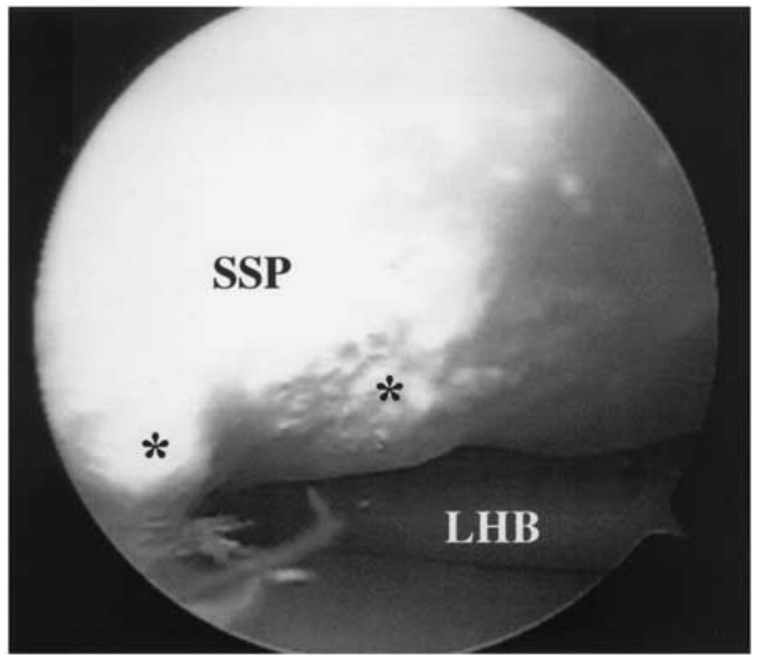

Figure 1 Articular side of supraspinatus (SSP) tendon containing tophaceous material (asterisk). LHB, Long head of biceps tendon.

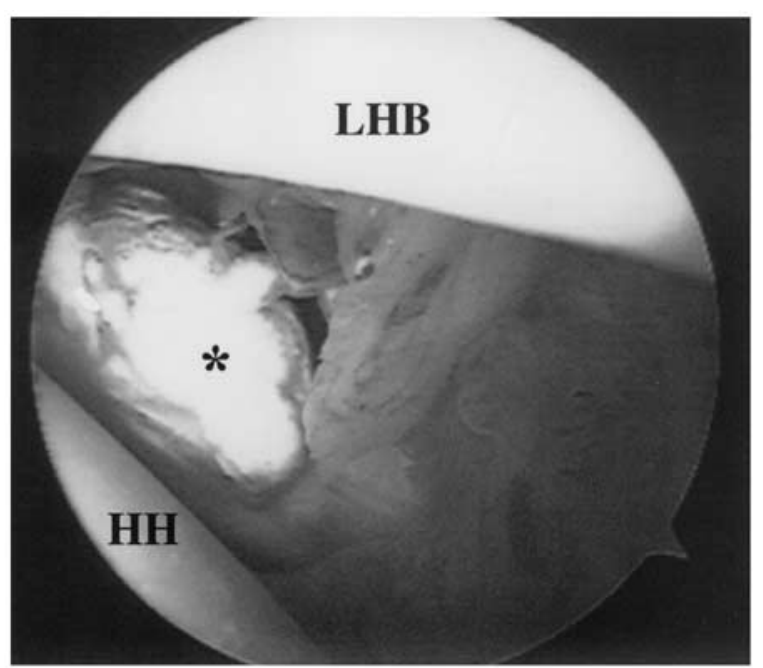

Figure 2 Large gouty tophus (asterisk) at upper border of subscapularis tendon, with associated synovitis. $H H$, Humeral head; $L H B$, long head of biceps tendon.

function. No attempts were made to remove the tophaceous deposits from the rotator cuff. Having dealt with the patient's secondary impingement, his rotator cuff function was improved with physiotherapy and his hyperuricemia treated with appropriate medication.

This appears to be the first case of tophaceous gout affecting the rotator cuff or glenohumeral joint reported in the literature. However, the presence of gouty tophi as a cause of impingement may be underdiagnosed in patients with longstanding and/or untreated disease.

\section{REFERENCES}

1. Akizuki S, Matsui T. Entrapment neuropathy caused by tophaceous gout. J Hand Surg [Br] 1984;9:331-2.

2. Chen CK, Yeh LR, Pan HB, et al. Intra-articular gouty tophi of the knee: CT and MR imaging in 12 patients. Skeletal Radiol 1999; 28:75-80

3. Duprez TP, Malghem J, Vande Berg BC, et al. Gout in the cervical spine: MR pattern mimicking diskovertebral infection. Am J Neuroradiol 1996; 17:151-3

4. Espinosa Morales R, Escalante A. Gout presenting as non-union of a patella fracture. J Rheumatol 1997;24:1421-2.

5. Fam AG, Assaad D. Intradermal urate tophi. J Rheumatol 1997; 24: $1126-31$

6. Gerster JC, Landry M, Duvoisin B, Rappoport G. Computed tomography of the knee joint as an indicator of intraarticular tophi in gout. Arthritis Rheum 1996;39: 1406-9.

7. Kelly IG. Arthritis of the shoulder joint complex. In: Kelly IG, editor. The practice of shoulder surgery. Oxford: Butterworth-Heinemann; 1993. p. 206-40.

8. Lagier R. Case report 591: osteoarthrosis $(O A)$ of the hip associated with microscopic gouty tophi. Skeletal Radiol 1990; 19:6972.

9. Liu K, Moffatt EJ, Hudson ER, Layfield LJ. Gouty tophus presenting as a soft-tissue mass diagnosed by fine-needle aspiration: a case report. Diagn Cytopathol 1996; 15:246-9.

10. Mahoney PJ, James PD, Howell CJ, Swannell AJ. Spontaneous rupture of the Achilles tendon in a patient with gout. Ann Rheum Dis 1981;40:416-8.

1 1. McCarthy DJ. Crystals and arthritis. Dis Mon 1994;40:253-99.

12. McDonald E, Marino C. Stopping progression to tophaceous gout. When and how to use urate-lowering therapy. Postgrad Med 1998;104:117-20, 123-24, 127.

13. Murshid WR, Moss TH, Ettles DF, Cummins BH. Tophaceous gout of the spine causing spinal cord compression. Br J Neurosurg 1994;8:751-4.

14. Petersson CJ. Painful shoulders in patients with rheumatoid arthritis. Scand J Rheumatol 1986; 15:275-9.

15. Popp JD, Bidgood WD Jr, Edwards NL. Magnetic resonance imaging of tophaceous gout in the hands and wrists. Semin Arthritis Rheum 1996;25:282-9.

16. Shmerling RH, Stern SH, Gravallese EM, Kantrowitz FG. Tophaceous deposition in the finger pads without gouty arthritis. Arch Intern Med 1988;148:1830-2.

17. Surprenant MS, Levy AL, Hanft JR. Intraosseus gout of the foot: an unusual case report. J Foot Ankle Surg 1996;35:237-43.

18. Yu JS, Chung C, Recht M, Dailiana T, Jurdi R. MR imaging of tophaceous gout. AJR Am J Roentgenol 1997; 168:523-7. 